\title{
HYDRAULICS RESEARCH IN GREAT BRITAIN WORK OF THE HYDRAULICS RESEARCH ORGANIZATION
}

\author{
By F. H. ALLEN \\ Assistant Director
}

$\mathrm{T}$ HE Hydraulics Research Organization of the Department of Scientific and Industrial Research was brought into being in 1947 in order to undertake research into open-channel flow, and, in particular, into the manifold problems of loose-boundary hydraulics as these are met in rivers, estuaries and coastal waters. Since that time, the Organization has expanded steadily until it now has a staff of about 130 and occupies a 90-acre site at Howbery Park, near Wallingford, Berkshire. The director of the Hydraulics Research Station is Sir Claude Inglis, formerly director of the Indian Waterways Experimental Station at Poona. The Station resembles the other research establishments of the Department of Scientific and Industrial Research in that its programme is controlled by a board of eminent engineers and scientists serving in an honorary capacity.

During 1947-51 the new Organization worked in cramped and temporary quarters at the National Physical Laboratory, while the new research station was planned and constructed at Wallingford. 'The Organization was transferred to Wallingford from 1951 and has been operating there in full strength since the summer of 1952. The nineteenth-century Manor House of Howbery Park has been converted for use as offices, and also includes the library, drawing office and canteen. In the first years at Wallingford, much of the work was carried out on the open-air research facilities, which were available long before the main covered accommodation which is now the nucleus of the Station. These open-air facilities include two large wave basins, each measuring $80 \mathrm{ft}$. by $125 \mathrm{ft}$. and equipped with permanent wavegenerating machinery, and a pair of unusually long experimental flumes or channels of rectangular crosssection, one $5 \mathrm{ft}$. and the other $12 \mathrm{ft}$. in width and both approximately $350 \mathrm{ft}$. in length. The wave basins are used for model investigations of harbours and for loose-boundary studies of the formation, development and protection of beaches. The channels are devoted to basic research into factors affecting the regime shapes and slopes of alluvial channels. For some time from 1952 it was also necessary to make use of existing temporary accommodation in the form of small precast concrete sheds. A valuable wave tank, $10 \mathrm{ft}$. wide and $54 \mathrm{ft}$. long, was constructed in one of these buildings and has since been used for a variety of investigations, including studies of the stability of various breakwater sections and experiments to determine how the rate at which water particles drift in the presence of waves varies with depth. Certain small models and experimental flumes were also built in temporary sheds at this period.

The major part of the permanent experimental accommodation of the Station becamo available for use only in January 1955. The Main Hall as it now stands measures $300 \mathrm{ft}$. by $200 \mathrm{ft}$., and the interior is unobstructed except for two columns supporting the roof. The ceiling is about $25 \mathrm{ft}$. above floor-level.
This impressive building is known as Stage 1 of the Main Hall, and major extensions to it are planned for erection in further stages during the next decade, the overall length of the final structure being $700 \mathrm{ft}$. The Main Hall has a radiant heating system and ample supplies of water, electrical power and artificial light; it has provision for water storage and drainage below floor-level and photographic facilities at ceiling-level. 'Transporter gantries are also suspended from rails at ceiling height. The floor consists of consolidated earth, loosely stabilized with a cold bitumastic emulsion, and may be excavated as required for the construction of hydraulic models. As accommodation for hydraulic research, the build. ing has won the admiration of many home and overseas visitors, and the facilities it provides in this respect are undoubtedly second to none in quality and flexibility. Attached to the Main Hall is a subsidiary block in which the various workshops and smaller general-purpose laboratories (for mechanization, development of instruments, analysis of sediments and photographic processing) are houscd.

In addition to basic or background research on open-channel flow and wave action, the Station carries out a considerable amount of ad hoc or applied research-indeed, at the present time, about threequarters of the total effort of the establishment is devoted to applied research on specific problems of one kind or another. Typical objectives of these investigations are the dissipation of turbulence below falls, sluices and similar hydraulic structures, the prevention or reduction of flooding, the improvement of shipping channels in ports and estuaries by the control or reduction of siltation, the damping of waves entering harbour and river mouths, and the control or retardation of coast erosion by wave action and tidal currents. These studies are carried out--usually on a repayment basis-on behalf of government departments, river boards, port authorities, coastal protection and local authorities, consulting engineers and private individuals. Work is also carried out for overseas members of the Commonwealth and for certain foreign countries.

The laws of similitude as applied to hydranlic models are sufficiently well known to need no detailed exposition. It is sufficient to say that, as gravitational forces predominate in most of the problems with which the Station is concerned, the Froude law is of over-riding importance in experimental work with scale models. In the study of problems involving the scour, transport and deposition of channel-bed material, movable-bed models--moulded in sand, pumice or some such incoherent granular substance -are used. The limitations of similitude in such models are recognized, and have indeed been the subject of controversy ; but it is now well established that they are invaluable aids in the solution of complex problems of bed movement and siltation. The similitude which can be demonstrated to exist in movable-bed models has not yet been fully defined 
by a mathematical analysis, and experimental work on models of this type can therefore be described with some justice as being partly an art and partly a science. Certainly it is a field of work where wide experience is essential, and where results must be subjected to continual scrutiny and comparison with the known behaviour of the natural prototypes.

The concept of regime, first developed on an empirical basis from a study of canals in India, has been found to be of wide application in the field of loose-boundary hydraulics and is itself the subject of basic research at the Station. In its application to uni-directional flow in alluvial channels-an aspect of the subject which is receiving an increasing amount of attention in the United States-regime theory relates the width and depth of a channel to the water discharge, the slope of the water surface and the quantity and nature of material in movement on the bed and in suspension. The application of this theory to hydraulic models is in itself an obvious subject for research.

There would be little point in lis ing all the investigations now in progress at Wallingford, but some idea of the scope of the research programme may be given if a few of the major projects are singled out for mention. Thus in the realm of tidal flow in estuaries, two major investigations of siltation are in progress-one concerning the deterioration of the upper estuary of the Mersey, and the other being aimed at the stabilization and deepening of the shipping channel at and below the port of Chittagong on the Karnafuli River in East Pakistan. A tidal study of a different type is in progress in a rigid-bed model of the tidal Trent, where methods of protection against combinations of river and tidal flooding are being tested. A large proportion of the station's effort is devoted to studies of wave action. In one of the wave basins a large model of the proposed design for the new harbour to be built at I'ema, on the Gold Coast, is being examined to determine its behaviour under the influence of short-period and long-period waves. A model of a now sea wall for the Lincolnshire bank of the outer Humber is being subjected to two-dimensional tests in the 54 -ft. wave tank. 'The formation of a sand-bar across the entrance to Eyemouth Harbour in Berwickshire is boing studied in a $1 / 40$-scale model equipped with pneumatic wave generators. Investigations of river problems and hydraulic structures also figure largely in the Station's programme of applied research and experimentation. In conclusion, mention should be made of radioactive isotopes as tracers for indicating the movements of silt and sand, in the use of which the Hydraulics Research Station, in collaboration with the Atomic Energy Research Establishment at Harwell, has carried out valuable pioneering work.

\section{OBITUARIES}

Mr. John Evershed, C.I.E., F.R.S.

By the death on November 17 at the age of ninetytwo of John Evershed, we have lost the doyen of British astronomers. Born on February 26, 1864, at Gomshall in Surrey, he was educated privately and started to work in the chemical industry. He early developed an interest in astronomy and established his own observatory at Kenley in Surrey in 1890. In that year he became one of the founder members of the British Astronomical Association and director of the Section of Solar Spectroscopy. With a small telescope and a spectroscope of his own design and construction, and later with a spectroheliograph also built by himself, he recorded 11,000 solar prominences during his sixteen years work at Kenley. The Evershed solar spectroscope is still an instrument in use to-day.

In 1906 he was appointed assistant director of the Kodaikanal Observatory; in 1911 he succeeded Michie Smith as director, retiring to England in 1923, when he was created C.X.E. in recognition of his work in India. At Kodaikanal he continued his work on prominences and with Mrs. Evershed he published an important memoir on the distribution of prominences during the course of a solar cycle : they noted the excess of eastern over western prominences, the longward displacement of the lines in their spectra and the link between sunspots and metallic prominences. Evershed also greatly improved the quality of the spectroheliograms obtained at the Observatory. His work on sunspot spectra led to his best-known discovery, the radial motion of gases, outwards across the penumbra of a sunspot and inwards at higher levels in the solar atmosphere. This work, published in 1909 , led to his election to the Royal Society in 1915 and to the award of the
Gold Medal of the Royal Astronomical Society in 1918.

Other work carried out by Evershed at Kodaikanal included studies of solar rotation, of the spectra of comets, Venus and Nova Aquilse 1918, of the displacement of lines to the red at the centre and limb of the Sun. He also chose a site for the Cawthron Observatory in New Zealand and travelled to the Vale of Kashmir to find a site with first-class seeing for a solar observatory in India. $\mathrm{He}$ observed eclipses in Norway, 1896; India, 1898; Algeria, 1900 ; Spain, 1905; Australia, 1922 ; and Yorkshire, 1927. Among his eclipse results were tho first record of the chromospheric continuous spectrum at the head of the Balmer series and his successful securing of long exposures on the chromosphere by stationing himself close to the edge of the belt of totality.

On his return from India, Evershed settled at Ewhurst in Surrey, where he built himself an observatory for solar work, continuing to obtain high-class spectroheliograms and high-dispersion solar spectra. His chief point of interest lay in exact wave-lengths of lines in the spectra of prominences and of the centre and limb of the solar disk. In a series of papers, giving measures of the highest degrees of accuracy and continuing until the year 1949, he discussed the varying displacements of lines to the red. He reached the final conclusion that the Einstein gravitational effect was the main cause of the displacements, though the result was modified by Doppler and Lindholm effects. $\mathrm{He}$ also examined some Mount Wilson plates that had been used to determine the general magnetic field of the Sun and concluded that the observed slight displacements were due to localized Doppler effects. 